\title{
Focus on Microalbuminuria to Improve Cardiac and Renal Protection
}

\author{
Paul E. de Jong Ron T. Gansevoort \\ Division of Nephrology, Department of Medicine, University Medical Center Groningen, \\ Groningen, The Netherlands
}

\section{Key Words}

Microalbuminuria - Estimated glomerular filtration rate •

Chronic kidney disease $\cdot$ Screening

\begin{abstract}
With the recent attention to diagnose earlier stages of chronic kidney diseases (CKD), most attention focuses on screening for an impaired estimated glomerular filtration rate (eGFR), i.e. CKD stages 3-5. Less attention is given to the impact of the urinary leakage of albumin. Its presence is not taken into account in the definition of stages 3-5, but only required to diagnose stages 1 and 2 . As in stages 1 and 2 CKD, eGFR is not or only modestly impaired, these stages are generally considered to have a relatively better prognosis. In this review, we will show evidence that screening for albuminuria may be of great benefit, not only as an argument to start treatment to prevent progressive renal function loss, but also to prevent cardiovascular events.
\end{abstract}

Copyright $\odot 2009$ S. Karger AG, Basel

\section{Introduction}

Proteinuria, the loss of proteins in urine, is one of the hallmarks of patients with kidney disease. Nephrotic syndrome, i.e. the loss of $>3$ g protein per day, was often the presenting symptom of a patient with glomerular or interstitial renal disease. In the last decades of the 20 th century, it became clear that the amount of proteinuria was directly associated with the severity of the renal function loss in the years after the first diagnosis. Moreover, it became clear that the extent to which treatment with antihypertensive agents lowers proteinuria, in particular blockers of the renin-angiotensin system in combination with diuretics, determines the effects of these drugs to prevent progressive renal function decline. The beneficial effects of such treatments to prevent end-stage renal disease (ESRD) may partly explain the trend that the number of patients reaching ESRD due to the classical renal diseases, as glomerulonephritis and type 1 diabetes, is presently diminishing [1]. On the other hand, however, the number of patients reaching ESRD due to type 2 diabetes, hypertension and generalized atherosclerosis is constantly increasing [1]. The latter is not unexpected as these patients generally are not diagnosed with the underlying disease, or - if diagnosed - are not monitored for their kidney function.

This is in fact the major boost behind the activities of various institutions to promote campaigns to detect chronic kidney disease (CKD) in an early phase. To that purpose the KDOQI published guidelines to define and to diagnose CKD. Since then, many efforts have been undertaken to detect subjects with CKD stage 3-5, i.e., subjects with an estimated glomerular filtration rate (eGFR) $<60 \mathrm{ml} / \mathrm{min} / 1.73 \mathrm{~m}^{2}$. Because GFR decreases with age, and is lower in women when compared to men, this type of screening results in the detection of a group of mostly

\section{KARGER \\ Fax +4161306 1234 E-Mail karger@karger.ch} www.karger.com
(C) 2009 S. Karger AG, Base $1660-2110 / 09 / 1113-0204 \$ 26.00 / 0$

Accessible online at: www.karger.com/nec
Prof. Dr. Paul E. de Jong

Division of Nephrology, Department of Medicine

University Medical Center Groningen, Hanzeplein 1

NL-9713 EZ Groningen (The Netherlands)

Tel. +31 50361 2955, Fax +31 50361 9310, E-Mail p.e.de.jong@int.umcg.nl 
elderly and frequently female subjects. Clinical practice and epidemiological studies have taught us that these subjects often have a fairly stable renal function over time. As a consequence there is much controversy whether this is the optimal approach to detect subjects at risk for ESRD [2]. Surprisingly, in this respect, less attention is given to the detection of subjects with stage 1 and 2 CKD, that is, patients with signs of renal damage but with still normal or only modestly impaired eGFR. As albuminuria, compared to erythrocyturia or abnormalities on ultrasonography, is the manifestation of chronic kidney damage easiest to be measured, we hypothesize that screening for an elevated albuminuria is a better approach to detect subjects at risk for progressive CKD.

\section{Microalbuminuria - The Consequence of Just Renal or of Generalized Vascular Damage?}

Though the only difference between micro- and macroalbuminuria is the amount of albumin excreted in the urine, $30-300$ versus $>300 \mathrm{mg} /$ day, it is generally expected not to be likely that microalbuminuria is a manifestation of glomerular damage, as the proximal tubule has an extensive potential to reabsorb albumin from the glomerular ultrafiltrate. On the other hand, there is evidence that microalbuminuria may be the consequence of generalized endothelial damage, thus not limited to the renal endothelium only. This is suggested from the Steno hypothesis arguing that diabetes leads to a generalized reduction of negative charges of extracellular matrix and plasma membranes, reflecting qualitative changes in the composition of the membranes severe enough to induce changes in permeability [3]. In line with this hypothesis, the presence of albuminuria in diabetes [4] and hypertension [5] is associated with markers of endothelial dysfunction.

If then assuming that microalbuminuria is a manifestation of generalized endothelial damage, it still is difficult to imagine why loss of albumin from the glomerulus is so closely associated with the vascular prognosis, when most of the albumin is next reabsorbed in the tubule. This can in fact be explained when tubular dysfunction instead of glomerular loss is adopted as the main determinant of the level of albuminuria. There is indeed evidence to support this theory, as tubular abnormalities are present early in the course of diabetes [6] and as tubular degradation of albumin also is inhibited in diabetic nephropathy [7]. The hypothesis that microalbuminuria might be considered as a tubular defect more than as a glomerular defect, and that microalbuminuria is related to systemic vascular prognosis more than to only renal prognosis, may point to the tubular hypoxia hypothesis as a mechanism underlying the association between microalbuminuria and both renal and vascular prognoses. Generalized endothelial damage may well impair blood flow in peritubular capillaries, which will result in tubular interstitial damage, interstitial fibrosis and impaired oxygen diffusion and the supply to tubular cells. This may impair the tubular epithelial albumin reabsorption [8].

\section{Microalbuminuria - How Reliable Is Its Diagnosis?}

Albuminuria can semiquantitatively be measured using test strips. These strips are relatively cheap, but have limited sensitivity and specificity [9]. Another option is measurement of urinary albumin concentration (UAC) with a point-of-care device. This device offers the possibility to measure UAC at the doctor's office. Results can immediately be used for clinical decision-making. Test characteristics of these devices are almost similar to that of the gold standard, being a measurement of UAC by radioimmunoassay or nephelometry [10]. The most used is measurement of albumin in a spot urine sample, preferably a first morning urine void [11]. A UAC of $>20$ $\mathrm{mg} / \mathrm{l}$ in such a simple and relatively cheap collected first morning urine void showed in a European study a sensitivity of $69 \%$ and a specificity of $96 \%$ to diagnose a 24 hour urinary albumin excretion of $>30 \mathrm{mg} / 24 \mathrm{~h}$ in two consecutive 24-hour urine samples [12]. These data are comparable to those in an Indo-Asian population. In that study the sensitivity and specificity of a UAC were 37 and $97 \%$, respectively, for women and 69 and 94\%, respectively, for men [13]. A drawback of this approach is that there will be false positive results. Since the consequence of having a 'positive' first morning void urine sample is just the need to repeat urine collections in a more accurate fashion, we feel that the limitation of this approach is acceptable when promoting population-based screening for albuminuria.

Reluctance to implement measurement of albuminuria in population studies is also based upon questions regarding the reproducibility of the test result. It has been shown that the within-person coefficient of variation between two consecutive 24 -hour UACs is $19.2 \%$, between two albumin creatinine ratios $13.8 \%$, and between two 24-hour albumin excretions $14.3 \%$ [14]. These figures may seem high, however, the chances that by repeat measurement subjects change class, i.e. going from normal to 
microalbuminuric, or vice versa, are small [11]. Measurement of UAC in fresh urine samples is to be preferred over measurement in samples that have been stored frozen, as the receiver-operating characteristics of a UAC of fresh urine samples to predict mortality was $0.80 \pm 0.014$, which was significantly better compared to $0.74 \pm 0.016$ for frozen samples $(\mathrm{p}=0.006)$ [15].

Various risk factors have been found to be associated with an elevated albuminuria (see table 1) [16]. Discussion of these associations is out of the scope of this review. As exercise and inflammation are also known to influence urinary albumin excretion, it should be realized that urine collection for albuminuria testing should be avoided after heavy exercise and whenever acute inflammatory processes are present.

Another topic that should be addressed is the reversibility in time of albuminuria. While this is well known for diabetes [17], the phenomenon is also manifest in the general population [16]. It has been shown that progression or regression of albuminuria class $(0-15,15-30,30-$ 300 or $>300 \mathrm{mg} /$ day, respectively) may both occur within a 4 -year period in about $10 \%$ of the subjects. The changes in fasting glucose and in blood pressure as well as the start of antihypertensives were associated with the changes in a urinary albumin excretion class multivariate model [18], however, the role of changes in BMI in this multivariate model was marginal. In a separate analysis to study the impact of the extremes of changes in body weight, that is in subjects who lost or gained more than $10 \mathrm{~kg}$ over a 4-year period, changes in body weight ran parallel with changes in albuminuria, which could not fully be attributed to the impact of changes in body weight on classical cardiovascular (CV) risk factors. In contrast, the data suggested that obesity-related changes in inflammatory markers may underlie the effects of body weight changes on changes in albuminuria [19].

\section{Microalbuminuria - A Marker of CV Events}

The first evidence of a worse CV prognosis of subjects with microalbuminuria was derived from data in patients with type 1 and type 2 diabetes. Shortly thereafter similar data were published for the presence of microalbuminuria in hypertension [20], in the elderly [21] and in the general population [22]. The increased vascular risk seems comparable for both cardiac and cerebrovascular events [20]. Interestingly, the level of eGFR has also been found associated with an increased risk for CV events [23]. As many patients with stage $3 \mathrm{CKD}$ have microalbu-
Table 1. Risk factors associated with elevated albuminuria

\begin{tabular}{|c|c|c|}
\hline \multirow[t]{2}{*}{ Non-modifiable } & \multicolumn{2}{|l|}{ Modifiable } \\
\hline & $\begin{array}{l}\text { well } \\
\text { documented }\end{array}$ & likely \\
\hline Race/ethnicity & diabetes & hyperlipidemia \\
\hline Male gender & hypertension & high salt (and protein) diet \\
\hline Older age & obesity & oral contraceptives \\
\hline Low birth weight & smoking & hormone replacement therapy \\
\hline
\end{tabular}

minuria, it is of importance to study to what extent in those subjects the increased CV risk is related to either the lower eGFR or the increased albuminuria. Both in a cohort of subjects with preexisting coronary heart disease [24] as in a general population cohort [25] the risk for CV events was not increased in subjects with stage 3 CKD without albuminuria as compared to subjects with normal renal function and without albuminuria, while the risk was clearly elevated in stage 3 CKD subjects with increased urinary albumin loss. Moreover, in patients with stage 1 and $2 \mathrm{CKD}$, thus those with (nearly) normal eGFR but with increased albuminuria, the risk was also elevated as compared to those without CKD [24, 25]. In a recent publication of the PREVEND cohort, it was shown that the increased CV risk in subjects with stage $3 \mathrm{CKD}$ without albuminuria is not elevated compared to the subjects without CKD after age and sex adjustment. On the other hand, the CV risk for subjects with albuminuria is equally increased in stages 1, 2 and 3, thus independent of the level of eGFR [26].

Although microalbuminuria is independent from other known CV risk factors associated with CV prognosis, there is debate whether microalbuminuria (and other new biomarkers as $\mathrm{C}$-reactive protein, B-type natriuretic peptide, etc.) add to conventional risk scores to predict $\mathrm{CV}$ events. Some studies suggest that the new biomarkers add only little to the conventional ones [27], whereas other studies found a significant added value [28, 29]. These studies take into account the overall population. The more important question is whether assessment of albuminuria adds in subjects with an intermediate risk profile in the classical risk scores, in whom it is not clear that treatment should be instituted or not. To that purpose we studied the CV event rate (both fatal and non-fatal) in subjects with a SCORE function [30] of 5-10\%. In that group the subjects with microalbuminuria had a $33 \% \mathrm{CV}$ event rate in 10 years compared to $14 \%$ in the subjects with normoalbuminuria. These data make it clear that 
Fig. 1. The percentage of the population (values at the bottom) and the odds ratio (bars) for developing de novo CV events (left) and de novo CKD (right) after 6 years of follow-up in relation to baseline urinary albumin excretion (UAE). Data are derived from the PREVEND cohort of 8,592 subjects from the general population. De novo CKD is defined as GFR $<60 \mathrm{ml} /$ $\mathrm{min} / 1.73 \mathrm{~m}^{2}$ [derived from 34 ].

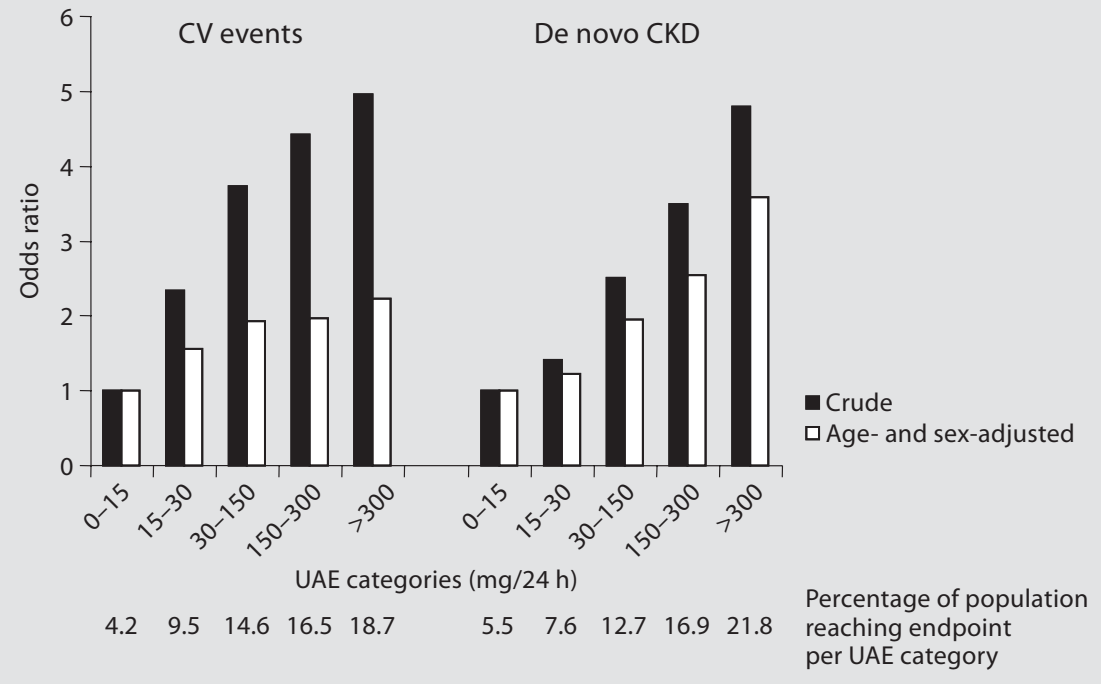

per UAE category knowledge on albuminuria status is indeed helpful to guide clinical decision-making.

If microalbuminuria is associated with a greater $\mathrm{CV}$ risk, the question is whether lowering of albuminuria is associated with a better CV prognosis. This has already been shown in subjects with macroalbuminuria. However, it was recently shown that lowering of albuminuria with an ACE inhibitor in subjects with an elevated albuminuria (15-300 mg/day) was also associated with fewer $\mathrm{CV}$ events, especially in subjects with an albumin loss in the range of 50-300 $\mathrm{mg} /$ day [31].

\section{Microalbuminuria - A Marker of Progressive Renal Function Loss}

Although it is widely accepted that albuminuria in the ranges of macroalbuminuria and nephrotic range proteinuria is the best predictor for progressive loss of renal function in subjects with known kidney disease, less data are available that document the association between microalbuminuria and progressive renal function loss. It has, however, recently been shown that microalbuminuria also predicts the de novo development of a stage 3 or worse CKD [32]. As it takes many years to progress to ESRD in subjects without known kidney disease, the impact of microalbuminuria as a predictor for progressive renal function loss can be better judged by calculating the eGFR slope over time. Brantsma et al. [26] recently showed that the eGFR slope over time is more negative in subjects with microalbuminuria compared to those without microalbuminuria, independent of the baseline level of eGFR. Moreover, similarly as with respect to future CV events, it has been shown that the risk to develop ESRD is only marginally (2.4-fold) increased in stage $3 \mathrm{CKD}$ subjects without albuminuria, while it was 12 -fold increased in subjects with a GFR of $60-90 \mathrm{ml} / \mathrm{min}$ but with albuminuria, and 33-fold increased in stage 3 CKD subjects with albuminuria [33]. These data indicate that in stages 1-3 the level of albuminuria has more impact than the level of eGFR per se. If thus the level of albuminuria predicts both future CV and renal events, it is of interest to compare the impact of albuminuria regarding these various endpoints. This has been done in figure 1, showing the association of the level of albuminuria with the odds to develop a CV event and a renal event (defined as de novo development of an eGFR $<60 \mathrm{ml} / \mathrm{min} / 1.73 \mathrm{~m}^{2}$ ). The data show that the odds increase comparably for both endpoints [34]. The impact of the various stages of CKD for reaching both endpoints is also clear from figure 2. It shows the incidence rates (on a log scale) per CKD stage for both $\mathrm{CV}$ endpoints and renal endpoints (now defined as the need to start renal replacement therapy). The data show that the incidence of both endpoints in stage 1 or $2 \mathrm{CKD}$ is about comparably elevated as in stage $3 \mathrm{CKD}$ compared to subjects without CKD. The figure moreover shows that, while in the first three stages the risk to develop a CV event is much higher than to develop 
a renal event, the reverse is true in stages 4 and 5 . However, the risk to develop a renal event rises more steeply than the risk to develop a CV event already in the early stages, thus in the subjects with microalbuminuria [35]. This once more argues that screening for microalbuminuria is not only of relevance to identify subjects at risk for cardiovascular disease (CVD), but also to identify those at risk for ESRD!

If albuminuria is associated with an increased risk for progressive renal disease, it again is of importance to study whether treatment with an ACE inhibitor will prevent microalbuminuric subjects to progress to macroalbuminuria. Thus far, this has only been studied in type 2 diabetic subjects with microalbuminuria. An ACE inhibitor prevented in these subjects the progression of microto macroalbuminuria [36].

\section{Screening for Microalbuminuria: How Could It Be Organized and What Is the Benefit?}

In case screening for albuminuria is to be implemented, should we consider the option to screen every subject in a certain age range for the presence of microalbuminuria, or to screen on albuminuria and eGFR in specific subsets of the population, such as those with known or expected increased risk?

With respect to the first option, a general population screen on the presence of an elevated albuminuria, most studies that have been published on this issue used the classical proteinuria dipstick test [33, 37, 38]. This test of course has the disadvantage that it is only semiquantitatively measured, and moreover has a relatively low sensitivity and specificity. Another approach was chosen in the pre-selection phase of the PREVEND study. We invited all inhabitants of the city of Groningen aged 28-75 $(\mathrm{n}=85,421)$ to fill out a short questionnaire on the presence of CV risk factors and to collect a sample of a first morning urine void in a plastic tube. Both were sent to the central laboratory of our hospital by post. Altogether 40,856 subjects ( $48 \%$ of the invitees) responded [39]. Macroalbuminuria was diagnosed in $0.7 \%$ of these subjects and microalbuminuria in $7.2 \%$.

Of course the percentage of subjects with micro- or macroalbuminuria will be much higher when the screening is limited to subjects with a known or an expected increased risk. Although many guidelines advocate screening for albuminuria in subjects known to have diabetes, in subjects known to have hypertension or in subjects over a certain age (e.g. 55 years), it is unfortunately

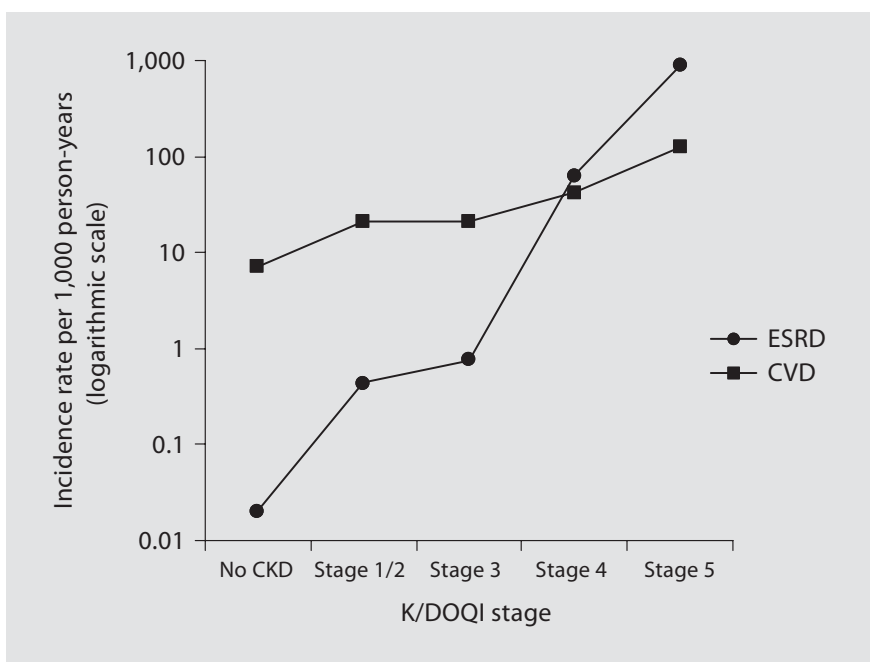

Fig. 2. Incidence of ESRD and CVD events according to baseline CKD stage. Data are derived from the PREVEND study [35].

not yet daily routine for many doctors. Preventive nephrology will already gain a lot when subjects who had a prior CV event or who are known to have diabetes and/or hypertension will indeed be screened for albuminuria and eGFR. Depending on the local situation with respect to the prevalence of diabetes and hypertension and of the age group addressed (those $>55$ or $>60$ years), this may yield information on evidence of CKD in $30-60 \%$ of the population. However, we should realize that many subjects unknowingly have diabetes and hypertension [40]. We recently showed that a population screening using a pre-selection of subjects with an UAC $>10 \mathrm{mg} / \mathrm{l}$ in a first morning urine void is more discriminating than screening the subjects with a prior $\mathrm{CV}$ event and with known diabetes and/or hypertension, and/or age $>55$ years. The first approach detects better the patients with CKD who are not yet on treatment and who experience more CV events in the future and who also experience more eGFR decline in the future, too [41].

Of course, screening programs to detect CKD will only be implemented if they have been proven cost-effective. In this respect, the study of Boulware et al. [42] in the USA is of interest. They showed that screening for dipstick-positive proteinuria in a general practitioner setting is not cost-effective to prevent ESRD. Cost-effectiveness was only reached when screening was limited to high-risk subgroups such as hypertensives and elderly. Another approach was used in the PREVEND study. All subjects were invited to deliver a first morning urine void 
to a central laboratory for quantitative measurement of UAC. Only the subjects with an elevated UAC were then invited for a visit to screen for CV risk factors and for signs of CKD and CVD, and those with an elevated albuminuria were treated with an ACE inhibitor. That screening and treatment program was proven to be cost-effective when it was calculated to prevent CV events [43]. These two studies show that cost-effectiveness can in a few years only be reached when it is expressed in terms of CV prevention, while the prevention of ESRD will become manifest only after a much longer time period. Second, these studies show that pre-selection of the population will increase effectiveness.

\section{Conclusion}

In our opinion the medical society should, when discussing possibilities for screening and prevention, not only pay attention to estimating GFR in individuals, but focus more on assessing their albuminuria status. Recent studies have shown that higher levels of albuminuria predict the occurrence of renal function loss and CV events, and that moderately impaired renal function (K/DOQI stage $3 \mathrm{CKD}$ ) is no such risk factor when albuminuria is absent. Besides being a valuable risk predictor in individual subjects that present themselves at a doctor's office, albuminuria can also be used to organize CKD screening. The population at large, or certain high-risk subgroups, could be asked to collect a urine sample and to send this sample to a central laboratory for assessment of albuminuria. Those with elevated levels will be asked to collect additional urine samples for confirmation. If abnormal albuminuria is confirmed, subjects will be invited to a screening facility where the presence of other $\mathrm{CV}$ risk factors will be assessed. When present, these risk factors should be treated, given the CV and renal risk entailed by higher levels of albuminuria. Using such a screening approach, albuminuria measurement will thus be the starting point to obtain someone's health $\mathrm{ABCDE}$, being the acronym for Albuminuria, Blood pressure, Cholesterol, Diabetes and Estimated GFR.

\section{References}

1 Gansevoort RT, van der Heij B, Stegeman CA, de Charro FT, Nieuwenhuizen MG, de Zeeuw D, de Jong PE: Trends in the incidence of treated end-stage renal failure in the Netherlands: hope for the future? Kidney Int Suppl 2004;92:S7-S10.

-2 Glassock RJ, Winnearls C: An epidemic of chronic kidney disease: fact or fiction? Nephron Dial Transplant 2008;23:1117-1121.

-3 Deckert T, Feldt-Rasmussen B, Borch-Johnsen K, Jensen T, Kofoed-Enevoldsen A: Albuminuria reflects widespread vascular damage. The Steno hypothesis. Diabetologia 1989;32:219-226.

4 Stehouwer CDA, Fischer HRA, van Kuijk AWR, Polak BC, Donker AJ: Endothelial dysfunction precedes the development of microalbuminuria in insulin-dependent diabetes mellitus. Diabetes 1995;44:561-564.

5 Pedrinelli R, Giampietro O, Carmassi F, Melillo E, Dell'Omo G, Catapano G: Microalbuminuria and endothelial dysfunction in essential hypertension. Lancet 1994;344: 14-18.

6 Gibb DM, Tomlinson PA, Dalton NR, Turner C, Shah V, Barratt TM: Renal tubular proteinuria and microalbuminuria in diabetic patients. Arch Dis Child 1989;64:129-134.
-7 Osicka TM, Houlihan CA, Chan JG, Jerums G, Comper WD: Albuminuria in patients with type 1 diabetes is directly linked to changes in the lysosome-mediated degradation of albumin during renal passage. Diabetes 2000;49:1579-1584.

$>8$ Nangaku M: Chronic hypoxia and tubulointerstitial injury: a final common pathway to end-stage renal failure. J Am Soc Nephrol 2006;17:17-25.

$\checkmark 9$ Webb DJ, Newman DJ, Chaturvedi N, Fuller JH: The use of the Micral-Test strip to identify the presence of microalbuminuria in people with insulin dependent diabetes mellitus participating in the EUCLID study. Diabetes Res Clin Pract 1996;31:93-102.

10 Lambers Heerspink HJ, Witte EC, Bakker SJ, de Jong PE, de Zeeuw D, Gansevoort RT: Screening and monitoring for albuminuria: the performance of the HemoCue point-ofcare system. Kidney Int 2008;74:377-383.

11 Witte EC, Lambers Heerspink HJ, Bakker SJL, de Jong PE, de Zeeuw D, Gansevoort RT: First morning voids or spot urine samples for determination of microalbuminuria? J Am Soc Nephrol 2008 (in press).

12 Gansevoort RT, Verhave JC, Hillege HL, Burgerhof JG, Bakker SJ, de Zeeuw D, de Jong PE: The validity of screening based on spot morning urine samples to detect subjects with microalbuminuria in the general population. Kidney Int Suppl 2005;94:S28S35.
13 Jafar TH, Chaturvedi N, Hatcher J, Levey AS: Use of albumin creatinine ratio and urine albumin concentration as a screening test for albuminuria in an Indo-Asian population. Nephrol Dial Transplant 2007;22:21942200.

14 Gansevoort RT, Brinkman JW, Bakker SJL, de Jong PE, de Zeeuw D: Evaluation of measures of urinary albumin excretion in epidemiologic studies. Am J Epidemiol 2006;164: 725-727.

15 Brinkman JW, de Zeeuw D, Duker JJ, Gansevoort RT, Kema IP, de Jong PE, Bakker SJL: Prolonged frozen storage of urine reduces the predictive value of albuminuria for mortality. Clin Chem 2007;53:153-154.

16 De Jong PE, Brenner BM: From secondary to primary prevention of progressive renal disease: the case for screening for albuminuria. Kidney Int 2004;66:2109-2118.

${ }_{17}$ Perkins BA, Ficociello LH, Silva KH, Finkelstein DM, Warram JH, Krolewski AS: Regression of microalbuminuria in type 1 diabetes. N Engl J Med 2003;348:2285-2293.

-18 Brantsma AH, Atthobari J, Bakker SJL, de Zeeuw D, de Jong PE, Gansevoort RT: What predicts progression and regression of urinary albumin excretion in the non-diabetic population. J Am Soc Nephrol 2007;18:637645. 
19 Bello AK, de Zeeuw D, El Nahas ME, Brantsma AH, Bakker SJL, de Jong PE, Gansevoort RT: Impact of weight change on albuminuria in the general population. Nephrol Dial Transpl 2007;22:1619-1627.

-20 Wachtell E, Ibsen H, Olsen MH, Borch-Johnsen K, Lindholm LH, Mogensen CE, Dahlof $B$, et al: Albuminuria and cardiovascular risk in hypertensive patients with left ventricular hypertrophy: the LIFE study. Ann Intern Med 2003;139:901-906.

-21 Damsgaard EM, Froland A, Jorgensen OD, Mogensen CE: Microalbuminuria as predictor of increased mortality in elderly people. BMJ 1990;300:297-300.

>22 Hillege HL, Fidler V, Diercks GF, van Gilst WH, de Zeeuw D, van Veldhuisen DJ, Gans ROB, Janssen WM, Grobbee DE, de Jong PE: Urinary albumin excretion predicts cardiovascular mortality in the general population. Circulation 2002;106:1777-1782.

23 Go AS, Chertow GM, Fan D, McCulloch CE, Hsu CY: Chronic kidney disease and the risks of death, cardiovascular events, and hospitalization. N Engl J Med 2004;351: 1296-1305.

-24 Tonelli M, Jose P, Curhan G, et al: Proteinuria, impaired kidney function, and adverse outcomes in people with coronary disease: analysis of a previously conducted randomised trial. Br Med J 2006;332:14261431.

-25 Foster MC, Hwang S-J, Larson MG: Crossclassification of microalbuminuria and reduced glomerular filtration rate. Arch Intern Med 2007;167:1386-1392.

26 Brantsma AH, Bakker SJL, Hillege HL, de Zeeuw D, de Jong PE, Gansevoort RT: Cardiovascular and renal outcome in subjects with K/DOQI stages 1-3 chronic kidney disease; the importance of urinary albumin excretion. Nephrol Dial Transplant 2008 (in press).

-27 Wang TJ, Gona P, Larson MG, Tofler GH, Levy D, Newton-Cheh C, Jacques PF, Rifai N, Selhub J, Robins SJ, Benjamin EJ, D’Agostino RB, Vasan RS: Multiple biomarkers for the prediction of first major cardiovascular events and death. N Engl J Med 2006;355:2631-2639.
28 Cao JJ, Biggs ML, Barzilay J, Konen J, Psaty BM, Kuller L, Bleyer AJ, Olson J, Wexler J, Summerson J, Cushman M: Cardiovascular and mortality risk prediction and stratification using urinary albumin excretion in older adults ages 68-102: the Cardiovascular Health Study. Atherosclerosis 2008;197 806-813.

29 Arnlöv J, Evans JC, Meigs JB, Wang TJ, Fox CS, Levy D, Benjamin EJ, D'Agostino RB, Vasan RS: Low-grade albuminuria and incidence of cardiovascular disease events in nonhypertensive and nondiabetic individuals: the Framingham Heart Study. Circulation 2005;112:969-975.

30 Conroy RM, Pyorala K, Fitzgerald AP, Sans S, Menotti A, De Backer G, De Bacuer D, Ducimetiere P, et al: Estimation of ten-year risk of fatal cardiovascular disease in Europe: the SCORE project. Eur Heart J 2003; 24:987-1003.

31 Asselbergs FW, Diercks GFH, Hillege HL, van Boven AJ, Janssen WMT, Voors AA, de Zeeuw D, de Jong PE, van Veldhuisen DJ, van Gilst WH; Prevention of Renal and Vascular End-Stage Disease Intervention Trial (PREVEND IT) Investigators: Effects of fosinopril and pravastatin on cardiovascular events in subjects with microalbuminuria. Circulation 2004;110:2809-2816

-32 Verhave JC, Gansevoort RT, Hillege HL, Bakker SJ, de Zeeuw D, de Jong PE: An elevated urinary albumin excretion predicts de novo development of renal function impairment in the general population. Kidney Int 2004;92:S18-S21.

33 Ishani A, Granditis GA, Grimm RH, Svendsen KH, Collins AJ, Prineas RJ, Neaton JD: Association of single measurements of dipstick proteinuria, estimated glomerular filtration rate, and hematocrit with 25-year incidence of end stage renal disease in the multiple risk factor intervention trial. J Am Soc Nephrol 2006;17:1444-1452.

34 De Jong PE, Gansevoort RT, Bakker SJL: Macroalbuminuria and microalbuminuria: do both predict renal and cardiovascular events with similar strength? J Nephrol 2007; 20:375-380.

-35 De Jong PE, van der Velde M, Gansevoort RT, Zocalli C: Screening for chronic kidney disease: where does Europe go? Clin J Am Soc Nephrol 2008;3:616-623.
36 Parving $\mathrm{HH}$, Lehnert $\mathrm{H}$, Brochner-Mortensen J: The effect of irbesartan on the development of diabetic nephropathy in patients with type 2 diabetes. N Engl J Med 2001;345:870-878.

37 Iseki K, Kinjo K, Iseki C, Takishita S: Relationship between predicted creatinine clearance and proteinuria and the risk of developing ESRD in Okinawa, Japan. Am J Kidney Dis 2004;44:806-814.

38 Viktorsdottir O, Palsson R, Andresdottir $\mathrm{MB}$, Aspelund T, Gudnason V, Indridason OS: Prevalence of chronic kidney disease based on estimated glomerular filtration rate and proteinuria in Icelandic adults. Nephrol Dial Transplant 2005;20:17991807.

39 Hillege HL, Janssen WM, Bak AA, Diercks GF, Grobbee DE, Crijns HJ, van Gilst WH, de Zeeuw D, de Jong PE: Microalbuminuria is common, also in a non-diabetic, non-hypertensive population, and an independent indicator of cardiovascular risk factors and cardiovascular morbidity. J Intern Med 2001; 249:519-526.

40 Hajjar I, Kotchen TA: Trends in prevalence, awareness, treatment, and control of hypertension in the United States. JAMA 2003; 290:199-206.

41 Van der Velde M, de Jong PE, Gansevoort RT: Comparison of screening approaches for chronic kidney disease. J Am Soc Nephrol 2008;19, ASN Abstract Issue (in press).

42 Boulware LE, Jaar BG, Tarver-Carr ME, Brancati FL, Powe NR: Screening for proteinuria in US adults: a cost-effectiveness analysis. JAMA 2003;290:3101-3114.

43 Atthobari J, Asselbergs FW, Boersma C, de Vries R, Hillege HL, van Gilst WH, Gansevoort RT, de Jong PE, de Jong-van den Berg LTW, Postma MJ, for the PREVEND IT Study Group: Cost-effectiveness of screening for albuminuria with subsequent fosinopril treatment to prevent cardiovascular events: a pharmacoeconomic analysis linked to the Prevention of Renal and Vascular EndStage Disease (PREVEND) study and the Prevention of Renal and Vascular end-Stage Disease Intervention Trail (PREVEND IT). Clin Ther 2006;28:432-444 


\section{Editorial Comment}

M. El Nahas, Sheffield

The minireview by De Jong and Gansevoort on albuminuria is a timely and excellent appraisal, by two leading world authorities in the field, of the issues relating to the diagnosis and prognostic values of albuminuria. Over the last decade, it has become increasingly recognised that albuminuria is commonly detected in the general population. A number of factors may contribute to that high prevalence (around 7\% in the PREVEND study) including ageing of the population and the rising prevalence of obesity and the metabolic syndrome. However, it is also important to recognise that microalbuminuria is often associated with a number of acute and chronic inflammatory conditions and that it can be reversible with control of the underlying inflammatory process. Caution therefore should be exerted in labelling individuals as suffering from CKD on the sole basis of transient or reversible microalbuminuria. This may have overinflated the prevalence of 'CKD'. Albuminuria is also associated with diffuse vascular pathology and endothelial dysfunction. This may explain its rise with age and the fact that albuminuria is increasingly recognised as a useful, additional, cardiovascular prognostic marker. By contrast, the evidence for microalbuminuria as an independent CKD prognostic marker is far from established. Also, a marker cannot claim to predict a disease as well as feature in its definition! Treating a marker also cannot cure the underlying disease unless it is a causative factor. This remains to be established for albuminuria. 